\title{
Modeling Two-Dimensional Erosion Process OVER INFILTRATING SURFACES
}

\author{
By Gokmen Tayfur ${ }^{1}$
}

\begin{abstract}
The physics-based modeling of the rainfall-runoff induced erosion process is accomplished. The existing one-dimensional erosion process equations are extended to two dimensions and kinematic wave approximation is used. The model assumes that suspended sediment does not affect flow dynamics. The model considers the effect of flow depth plus loose soil depth on soil detachment. Sensitivity analysis results indicate that the effects of the soil erodibility coefficient $(\eta)$ and exponent $\left(k_{1}\right)$ on sediment discharges are quite pronounced. On steep slopes, the effect of flow depth plus loose soil depth on sediment discharge is insignificant.
\end{abstract}

\section{INTRODUCTION}

Watershed sediment yield is a direct indication of surface erosion rates and is also the primary source of fine sediment being carried in most rivers. Surface erosion is the most fundamental type of soil loss in forest, agricultural, and urban watersheds (Li 1979).

Hydrologic processes of rainfall and runoff drive the surface erosion process. Surface erosion by water embodies the processes of detachment, transportation, and deposition of soil particles by the erosive and transport agents of raindrop impact and runoff over soil surface (Foster 1982). Detachment occurs when the erosive forces of raindrop impact and/or flowing water exceed the resistance of soil to erosion. Detached particles are carried downstream by overland flow. Deposition occurs when the sediment load exceeds the transport capacity (Foster 1982). Erosion not only reduces productivity of cropland but may also degrade water quality because of the association of pollutants to the fine sediments. Deposition in water conveyance structures such as irrigation canals, stream channels, reservoir, estuaries, and harbors reduces the capacity of these structures (Foster 1982).

Erosion on land surfaces has been experimentally studied by many researchers in laboratories and in the field (Kilinc and Richardson 1973; Abrahams et al. 1989; Govindaraju and Kavvas 1992). Physics-based mathematical modeling studies of rain-induced surface erosion have also been attempted by many researchers (Negev 1967; Foster and Meyer 1972; Govindaraju and Kavvas 1991). All of the above studies modeled the rain-induced surface erosion in one dimension. In reality however, most natural surfaces have irregular microtopography and, consequently, flow over these surfaces is mostly in two dimensions.

This study presents the two-dimensional modeling of raininduced erosion over land surfaces.

\section{MATHEMATICAL DEVELOPMENT}

There are two parts in modeling rain-induced surface erosion: flow dynamics and erosion dynamics. By solving the flow dynamics one obtains the flow depth and velocity fields on the land surface and the flow discharge from the land surface. The computed flow depth and velocity fields are, in turn, used for the erosion dynamics to predict the sediment concentration field on the land surface and sediment discharge from

\footnotetext{
${ }^{1}$ Assoc. Prof., Dept. of Civ. Engrg., Izmir Inst. of Tech., 35230 Cankaya, Izmir, Turkey.

Note. Discussion open until November 1, 2001. To extend the closing date one month, a written request must be filed with the ASCE Manager of Journals. The manuscript for this technical note was submitted for review and possible publication on February 25, 1998; revised July 18, 2000. This technical note is part of the Journal of Hydrologic Engineering, Vol. 6, No. 3, May/June, 2001. CASCE, ISSN 1084-0699/01/ 0003-0259-0262/\$8.00 + \$.50 per page. Technical Note No. 17782.
}

the land surface. This approach explicitly assumes that the sediment concentrations in the overland flow regime are sufficiently small so that the suspended sediment does not affect the flow dynamics. Under this assumption, one can simulate these two processes independently. This assumption has been commonly employed by researchers (Foster and Meyer 1972; Li 1979; Govindaraju and Kavvas 1991).

\section{Flow Dynamics}

Kinematic wave approximation (KWA) is used for modeling flow dynamics. The KWA equation in two dimensions is stated as (Tayfur and Kavvas 1994)

$$
\frac{\partial h}{\partial t}+\frac{\partial}{\partial x}\left(C_{x} h^{5 / 3}\right)+\frac{\partial}{\partial y}\left(C_{y} h^{5 / 3}\right)=(r-i)
$$

where

$$
\begin{aligned}
& C_{x}= \frac{S_{x}^{0.5}}{n\left[1+\left(\frac{S_{y}}{S_{x}}\right)^{2}\right]^{0.25}} \\
& C_{y}=\frac{S_{y}^{0.5}}{n\left[1+\left(\frac{S_{x}}{S_{y}}\right)^{2}\right]^{0.25}}
\end{aligned}
$$

where $h=$ overland flow depth (L); $r=$ rainfall intensity $(\mathrm{L} / \mathrm{T}) ; i=$ infiltration rate $(\mathrm{L} / \mathrm{T}) ; S_{x}=$ bed slope in $x$-direction (see Fig. 1); $S_{y}=$ bed slope in $y$-direction (see Fig. 1); and $n$ = Manning's roughness coefficient.

\section{Erosion Dynamics}

A physics-based, one-dimensional, erosion/sediment transport equation is already available in the literature (Foster and Meyer 1972; Li 1979; Woolhiser et al. 1990). The one-dimensional formulation by Woolhiser et al. (1990) is extended to two dimensions as follows:

$$
\frac{\partial(h c)}{\partial t}+\frac{\partial}{\partial x}\left(q_{x} c\right)+\frac{\partial}{\partial y}\left(q_{y} c\right)=\frac{1}{\rho_{s}}\left(D_{r d}+D_{s f}\right)
$$

where

$$
\begin{aligned}
& q_{x}=C_{x} h^{5 / 3} \\
& q_{y}=C_{y} h^{5 / 3}
\end{aligned}
$$

where $c=$ sediment concentration by volume $\left(\mathrm{L}^{3} / \mathrm{L}^{3}\right) ; \rho_{s}=$ sediment particle density $\left(\mathrm{M} / \mathrm{L}^{3}\right) ; q_{x}=$ unit flow discharge in $x$-direction $\left(\mathrm{L}^{2} / \mathrm{T}\right)$ (see Fig. 1$) ; q_{y}=$ unit flow discharge in $y$ direction $\left(\mathrm{L}^{2} / \mathrm{T}\right)$ (see Fig. 1$) ; D_{r d}=$ soil detachment rate by raindrops $\left(\mathrm{M} / \mathrm{L}^{2} / \mathrm{T}\right)$; and $D_{s f}=$ soil detachment/deposition rate by sheet flow $\left(\mathrm{M} / \mathrm{L}^{2} / \mathrm{T}\right)$. 

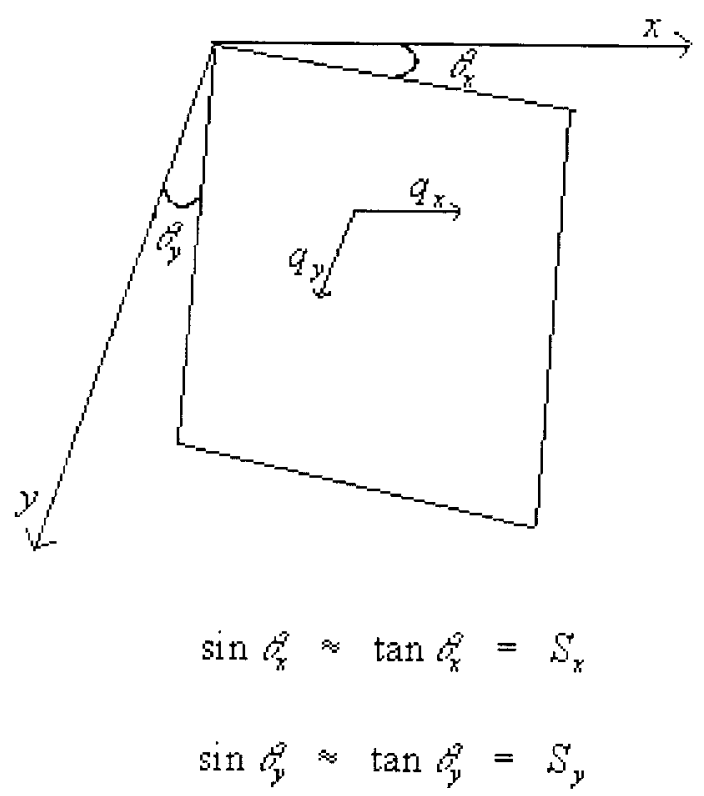

FIG. 1. Definition Sketch for Two-Dimensional Overland Flow

\section{Soil Detachment by Raindrops}

Soil detachment is a function of the erosivity of rainfall and the erodibility of soil particles. The erosivity is directly related to the energy produced by raindrop impact and is generally formulated as a power function of rainfall intensity, size of droplet, cover condition, and terminal velocity of the drop (Meyer and Weschmeier 1969). On a bare soil surface, detachment by raindrops can be expressed as (Li 1979)

$$
D_{r d}=\alpha r^{b}\left(1-\frac{z_{w}}{z_{m}}\right)
$$

where $\alpha=$ soil detachability coefficient that depends on the soil characteristics $\left(\mathrm{M} / \mathrm{L}^{2} / \mathrm{L}\right)$. Soil properties known to affect erodibility include primary particle size distribution, organic matter content, soil structure, content of iron and aluminum oxides, electro-chemical bonds, initial moisture content, and aging (Partheniades 1972). Sharma et al. (1993) obtained a range of $0.0006 \mathrm{~kg} / \mathrm{m}^{2} / \mathrm{mm}-0.0086 \mathrm{~kg} / \mathrm{m}^{2} / \mathrm{mm}$ for $\alpha$ for easily detachable soils and $0.00012 \mathrm{~kg} / \mathrm{m}^{2} / \mathrm{mm}-0.0017 \mathrm{~kg} / \mathrm{m}^{2} / \mathrm{mm}$ for less detachable soils. Note that in (7) $r$ is in $\mathrm{mm} / \mathrm{h} ; \alpha$ is in $\mathrm{kg} / \mathrm{m}^{2} / \mathrm{mm}$; and $D_{r d}$ is in $\mathrm{kg} / \mathrm{m}^{2} / \mathrm{h}$. The range for $\alpha$ obtained by Sharma et al. (1993) is in agreement with Foster (1982).

The variable $b=$ a constant whose range is $1-2$. From experimental studies, it is shown that $b=2$ (Meyer 1971; Foster 1982). Sharma et al. (1993) showed that the value of $b$ is in the range of $1.09-1.44$. Meyer (1981) obtained $b=1.8$ in his observed experimental work.

The variable $z_{w}=$ flow depth plus the loose soil depth (L); and $z_{m}=$ maximum penetration depth of the raindrop splash (L). Eq. (7) is valid when $z_{w}<z_{m}$, otherwise there is no detachment by the raindrops. According to Mutchler and Young (1975), $z_{m}$ can be equal to three times the median raindrop size, and the median raindrop size can be expressed as a power function of rainfall intensity. According to Li (1979)

$$
z_{m}=3\left(2.23 r^{0.182}\right)
$$

Note that in (8), $r$ is in $\mathrm{mm} / \mathrm{h}$ and $z_{m}$ is computed in $\mathrm{mm}$.

Eq. (7) expresses the detachment by raindrop impact as a power function of rainfall intensity, flow depth, and loose soil depth. As flow depth and loose soil depth increase, the penetration depth decreases and consequently the detachment by raindrop decreases.

\section{Soil Detachment/Deposition by Sheet Flow}

Soil detachment/deposition is caused by the interplay between shear stress exerted by water on the loose soil bed and the tendency of soil particles to settle under the force of gravity (Woolhiser et al. 1990). The soil detachment/deposition rate is proportional to the difference between the sediment transport capacity and the sediment load in the flow. This implies that the flow has the maximum eroding capacity when it is free of suspended sediment. When the sediment load is greater than the transporting capacity, deposition occurs. The soil detachment/deposition by sheet flow can be expressed as (Foster 1982; Govindaraju and Kavvas 1991)

$$
\begin{gathered}
D_{f d}=\beta\left(T_{c}-q_{s}\right) \\
q_{s}=\rho_{s} c q
\end{gathered}
$$

where

$$
q=\left(q_{x}^{2}+q_{y}^{2}\right)^{0.5}
$$

where $T_{c}=$ transport capacity of the sheet flow in the flow direction $(\mathrm{M} / \mathrm{L} / \mathrm{T})$ and $q_{s}=$ unit sediment discharge in the flow direction $(\mathrm{M} / \mathrm{L} / \mathrm{T})$. If the transport capacity exceeds the existing unit sediment discharge $\left(T_{c}>q_{s}\right)$, the flow will detach particles, otherwise it will deposit the particles. The value of $\beta=$ transfer rate coefficient may vary over a wide range depending on the soil type (1/L) (Govindaraju and Kavvas 1991). During deposition $\left(T_{c}<q_{s}\right), \beta$ is estimated as a function of particle fall velocity $\left(V_{f}\right)$, and the unit flow discharge in the flow direction $q$ as by Foster (1982) is

$$
\beta=\left(0.5 V_{f}\right) / q
$$

Particle terminal fall velocity may be estimated from particle density and size, assuming that the particles have drag characteristics and terminal fall velocities similar to those of spheres (Woolhiser et al. 1990)

$$
\begin{gathered}
V_{f}^{2}=\frac{4}{3} \frac{g\left(S_{s}-1\right) d}{D_{c}} \\
D_{c}=\frac{24}{R_{p m}}+\frac{3}{\sqrt{R_{p n}}}+0.34 \\
R_{p n}=\frac{V_{f} d}{v}
\end{gathered}
$$

where $g=$ gravitational acceleration $\left(\mathrm{L} / \mathrm{T}^{2}\right) ; S_{s}=$ particle specific gravity; $d=$ particle diameter $(\mathrm{L}) ; D_{c}=$ drag coefficient; $R_{p n}=$ particle Reynolds number; and $v=$ kinematic viscosity of water $\left(\mathrm{L}^{2} / \mathrm{T}\right)$. Sheet flow transport capacity is a function of several factors that include runoff rate, flow velocity and depth, slope steepness, roughness of the surface, transportability of detached soil particles, and the effect of raindrop impact. The basic relationship that does not take into consideration the effect of raindrop impact on transport capacity might be a typical sediment transport equation form of (Foster 1982)

$$
\begin{gathered}
T_{c}=\eta\left(\tau-\tau_{c r}\right)^{k_{1}} \\
\tau=\gamma h S \\
S=\left(S_{x}^{2}+S_{y}^{2}\right)^{0.5}
\end{gathered}
$$

where $\tau=$ shear stress which is the tractive force developed by the sheet flow to overcome the critical shear stress $\left(\mathrm{M} / \mathrm{L}^{2}\right)$; $\eta=$ soil erodibility coefficient that is a function of particle diameter and density. Foster (1982) suggests the value of 0.6 for $\eta$. The value $k_{1}=$ an exponent whose value varies between 1 and 2. Foster (1982) suggests the value of 1.5 for $k_{1}$. Li (1979) also used 1.5 for $k_{1} ; \gamma=$ specific weight of water $\left(\mathrm{M} / \mathrm{L}^{3}\right) ; S=$ bed slope in the flow direction; and $\tau_{c r}=$ critical 
shear stress that is a function of particle diameter and density $\left(\mathrm{M} / \mathrm{L}^{2}\right)$. Li (1979) expresses $\tau_{c r}$ as

$$
\tau_{c r}=\delta_{s}\left(\gamma_{s}-\gamma\right) d
$$

where $\delta_{s}$ is a constant dependent on flow conditions. Gessler (1965) shows that $\delta_{s}$ should be 0.047 for most flow conditions. The value $\gamma_{s}$ is the specific weight of sediment $\left(\mathrm{M} / \mathrm{L}^{3}\right)$ and $\tau_{c r}$ represents the resistancy of the soil against erosion. Critical shear stress is very small for cohesionless soils and is often neglected (Foster 1982).

\section{Solution Procedure}

Eqs. (1) and (4) are solved numerically by using the implicit centered finite difference method. The Newton-Raphson iterative technique is used to solve the set of nonlinear equations resulting from the implicit procedure. For solving (1) to obtain flow depths and unit flow discharges in $x$ - and $y$-directions, zero flow depth and zero-depth gradient boundary conditions were used as upstream and downstream boundary conditions, respectively. Similarly, for solving (4) to compute sediment concentrations and unit sediment discharges, zero sediment concentration and zero-sediment concentration gradient boundary conditions were used as upstream and downstream boundary conditions, respectively. As initial conditions, very thin layers of water $(0.001 \mathrm{~mm}$ flow depth) and a sediment concentration $\left(0.001 \mathrm{~L} / \mathrm{m}^{3}\right)$ were assumed to avoid singularity problem in the simultaneous numerical solutions of (1) and (4).

At $(k+1)$ time step the loose soil depth $\left(l_{d}\right)$ can be computed as

$$
l_{d}(k+1)=l_{d}(k)+\left(D_{r d}(k)+D_{f d}(k)\right) \Delta t / \rho_{s}
$$

The infiltration rate $(i)$ is modeled by the Green-Ampt filtration model, which has been found to have wide applicability for the modeling infiltration process (Rawls et al. 1983).

\section{ANALYSIS OF RESULTS}

Sensitivity analysis was performed in order to evaluate the effects of variations in major erosion/sediment transport model parameters on total sediment discharges. For this purpose, a 4-m-wide by $22-\mathrm{m}$-long hypothetical bare hillslope was considered. The hillslope was considered to have 5\% bed slope in $x$-direction and $8 \%$ bed slope in $y$-direction (see Fig. 1). The hillslope was subjected to $117 \mathrm{~mm} / \mathrm{h}$ of rainfall intensity for the duration of 6 minutes.

Fig. 2 shows the change in sediment discharge with respect to the change in the soil detachability coefficient $(\alpha)$. As seen in Fig. 2, the increase/decrease in soil detachability causes an increase/decrease in sediment discharge. However, the change in sediment discharge is more pronounced when the value of $\alpha$ is increased from 0.0022 to 0.0088 (Fig. 2).

Fig. 3 shows the change in sediment discharge with respect

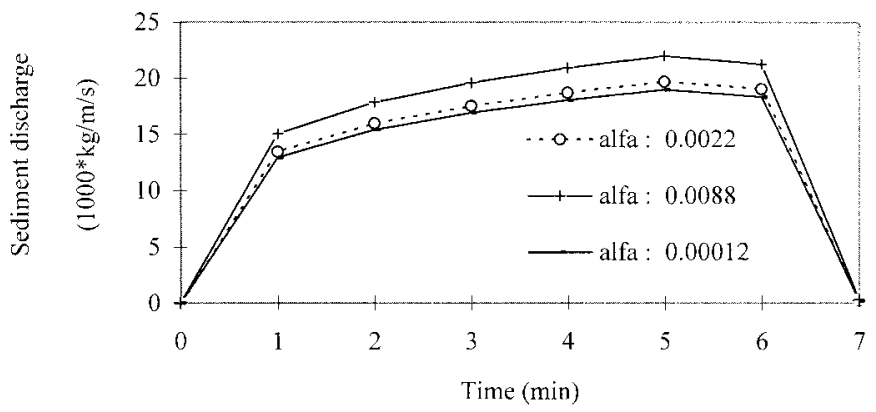

FIG. 2. Effect of Soil Detachability Coefficient $(\alpha)$ on Sediment Discharge to the change in the exponent $b$ of the rainfall intensity in (7). As seen in Fig. 3, the increase/decrease in $b$ causes an increase/decrease in sediment discharge. However, as it may be seen in Fig. 3, varying the value of $b$ between 1.0 and 1.8 does not cause a significant change in sediment discharge. On the other hand, when the value of $b$ exceeds 2.0 the change in sediment discharge becomes more significant (Fig. 3).

Fig. 4 shows the change in sediment discharge with respect to the change in the soil erodibility coefficient $(\eta)$. As seen in Fig. 4, the increase/decrease in soil erodibility causes a significant increase/decrease in sediment discharge. Increasing/ decreasing the value of $\eta$ twice/three times causes almost twice/three times increase/decrease in sediment discharge (Fig. 4).

Fig. 5 shows the change in sediment discharge with respect to the change in the exponent $k_{1}$ in (16). As seen in Fig. 5, the increase in $k_{1}$ causes a significant increase in sediment discharge. About an $18 \%$ increase in $k_{1}$ causes almost three times the decrease in sediment discharge, and about an $18 \%$ decrease in $k_{1}$ causes a three times increase in sediment discharge (Fig. 5).

The effect of flow depth plus loose soil depth on sediment discharge was also investigated. The model showed that for the case of steep slopes (more than 5\% in $x$ - and $y$-direction) there exists no such effect.

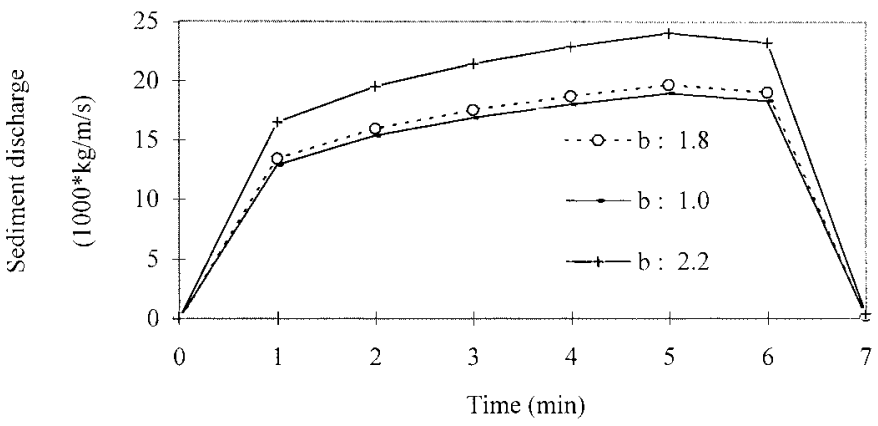

FIG. 3. Effect of Exponent $b$ in (7) on Sediment Discharge

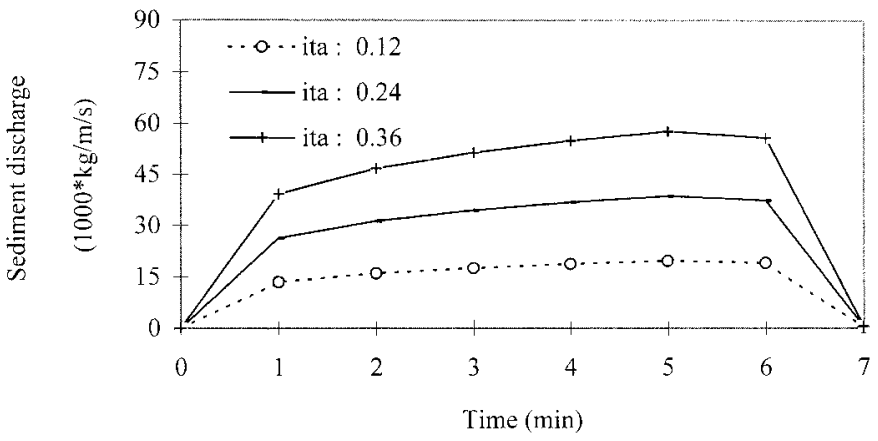

FIG. 4. Effect of Soil Erodibility Coefficient $(\eta)$ on Sediment Discharge

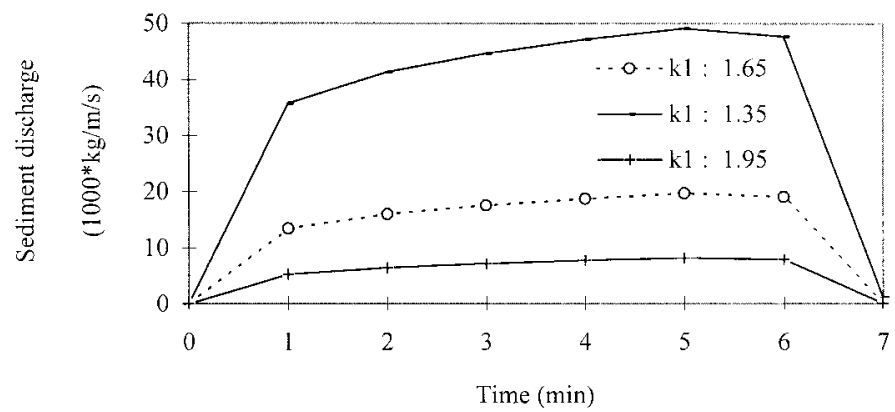

FIG. 5. Effect of Exponent $k_{1}$ in (16) on Sediment Discharge 


\section{CONCLUDING REMARKS}

In this study, rainfall-runoff induced surface erosion in two dimensions over infiltrating smooth bare surfaces was accomplished. The model is based on KWA, and it considers the soil detachment process by rain drops and the sheet flow and deposition process by sheet flow. During deposition, the transfer rate coefficient $\beta$ was computed as a function of particle fall velocity and unit flow discharge. Particle terminal fall velocity is computed as a function of particle Reynolds number, drag coefficient, and particle specific gravity and diameter. The model considers the effect of flow depth plus loose soil depth on soil detachment by raindrop impacts.

Sensitivity analysis results indicate that the parameters that are the most sensitive ones are the soil erodibility coefficient $(\eta)$ and the exponent $k_{1}$ in (16). When modeling of sheet erosion over steep bare slopes is performed, there is no need to consider the effect of flow depth plus loose soil depth on soil detachment. This is because on steep slopes the sheet flow depth is of the order of millimeters (even less than a millimeter). For example, under $117 \mathrm{~mm} / \mathrm{h}$ of rainfall, the model shows that the maximum flow depth is $1.26 \mathrm{~mm}$ over a 4.5 m-wide by $22-\mathrm{m}$-long steep plot that has a $1 \%$ slope in the $x$-direction and a $8.6 \%$ slope in the $y$-direction (Fig. 1). On the other hand, according to (8), the maximum penetration depth of a raindrop of $117 \mathrm{~mm} / \mathrm{h}$ of rainfall is about $16 \mathrm{~mm}$. This clearly shows that on steep slopes the maximum penetration depth of raindrops is much larger than the sheet flow depth. Hence the effect of flow depth on soil detachment by raindrops would be negligible on steep slopes.

\section{REFERENCES}

Abrahams, A. D., Parsons, A. J., and Luk, S. H. (1989). "Distribution of depth of overland flow on desert hillslopes and its implication for modeling soil erosion." J. Hydro., Amsterdam, 106(1), 177-184.

Foster, G. R. (1982). "Modeling the erosion process." Hydrologic modeling of small watersheds, C. T. Haan, H. P. Johnson, and D. L. Brakensiek, eds., ASAE, New York, 295-380.

Foster, G. R., and Meyer, L. D. (1972). "A closed-form soil erosion equation for upland areas." Sedimentation Symposium to Honor Prof. H. A. Einstein, H. W. Shen ed., Fort Collins, Colo., 12.1-12.9.

Gessler, J. (1965). "The beginning of bedload movement of mixtures investigated as natural armoring in channels." E. A. Prych, translator, W. M. Keck Laboratory of Hydraulics and Water Research, California Institute of Technology, Pasadena, Calif.

Govindaraju, R. S., and Kavvas, M. L. (1991). "Modeling the erosion process over steep slopes: Approximate analytical solutions." J. Hydro., Amsterdam, 127, 279-305.

Govindaraju, R. S., and Kavvas, M. L. (1992). "Characterization of the rill geometry over straight hillslopes through spatial scales." J. Hydro., Amsterdam, 130, 339-365.

Kilinc, M., and Richardson, E. V. (1973). "Mechanics of soil erosion from overland flow generated by simulated rainfall." Hydrology $\mathrm{Pa}$ pers, No. 63, Colorado State University.

Li, R. M. (1979). "Water and sediment routing from watersheds." Modeling of rivers, H. W. Shen ed., Wiley, New York, 9.1-9.88.

Meyer, L. D. (1971). "Soil erosion by water on upland areas." River mechanics, H. W. Shen, ed., Vol. 2, Fort Collins, Colo.

Meyer, L. D. (1981). "How rain intensity affects interrill erosion." Trans., ASAE, 26, 1472-1475.

Meyer, L. D., and Wischmeir, W. H. (1969). "Mathematical simulation of the process of soil erosion by water." Trans., ASAE, 12(6), 754762.

Mutchler, C. K., and Young, R. A. (1975). "Soil detachment by raindrops." Proc. of the Sediment-Yield Workshops, ARS-S-40, USDA, Oxford, Miss., 113-117.

Negev, N. (1967). "A sediment model on a digital computer." Tech. Rep. No. 76, Stanford University, Stanford, Calif., 109 pp.

Partheniades, E. (1972). "Results of recent investigation on erosion and deposition of cohesive sediments." Sedimentation, H. W. Shen, ed., Colo., 20.1-20.29.

Rawls, W. J., Brakensiek, D. L., and Miller, N. (1983). "Green-Ampt infiltration parameters from soils data." J. Hydr. Engrg., ASCE, 109(1), $62-70$.

Sharma, P. P. Gupta, S. C., and Foster, G. R. (1993). "Predicting soil detachment by raindrops." Soil Sci. Soc. Am. J., 57, 674-680.

Tayfur, G., and Kavvas, M. L. (1994). "Spatially averaged conservation equations for interacting rill-interrill area overland flows." $J$. Hydr. Engrg., ASCE, 120(12), 1426-1448.

Woolhiser, D. A., Smith, R. E., and Goodrich, D. C. (1990). "KINEROS, A kinematic runoff and erosion model: Documentation and user manual.” ASR-77, U.S. Department of Agriculture, Washington, D.C., 130 pp. 